\title{
Enhancing Interferometric SAR Performance over Sandy Areas: Experience from the TanDEM-X Mission
}

\author{
Michele Martone, Benjamin Bräutigam, Paola Rizzoli, Nestor Yague-Martinez, and Gerhard Krieger
}

\begin{abstract}
The TanDEM-X mission is served by two X-band synthetic aperture radar (SAR) satellites, which fly in close orbit formation acting as a large and flexible single-pass radar interferometer. The primary goal of the mission is the creation of a consistent and global digital elevation model (DEM). A very good and reproducible performance has been verified for most of the land masses. In this paper, a detailed performance analysis of TanDEM-X data is presented for sandy desert areas, which show a strong impact on the quality of spaceborne SAR surveys. The influence of several acquisition parameters on SAR and interferometric (InSAR) performance is evaluated by means of statistical analyses as well as long-term repeated acquisitions on defined test sites. Alternative processing approaches aiming at improving the quality of the interferometric products are presented, too. From the obtained analyses, a description of the scattering mechanisms occurring at $\mathrm{X}$-band over sandy surfaces is derived, which allows to plan a dedicated reacquisition of such areas with optimized imaging geometry in order to improve the quality of the final TanDEM-X DEM.
\end{abstract}

Index Terms-Synthetic aperture radar interferometry (InSAR), digital elevation model (DEM), TanDEM-X, deserts, performance.

\section{INTRODUCTION}

D IGITAL elevation models (DEMs) are of fundamental importance for a wide range of commercial and scientific applications. Many geoscience fields, such as hydrology, geomorphology, and land environment, require precise mapping of the Earth's surface and topography. In 2000, the Shuttle Radar Topography Mission (SRTM) produced the first near-global elevation data set (from $56^{\circ} \mathrm{S}$ to $60^{\circ} \mathrm{N}$ ) [1] at a horizontal resolution of $30 \mathrm{~m}$ using $\mathrm{C}$ - and $\mathrm{X}$-band (corresponding to wavelengths of 5.6 and $3.1 \mathrm{~cm}$, respectively). In 2010 the TanDEM-X (TerraSAR-X add-on for Digital Elevation Measurement) mission was launched, opening a new era in spaceborne radar remote sensing. Developed under a public-private partnership between the German Aerospace Center (DLR) and Astrium GmbH [2], TanDEM-X is the first operational bistatic synthetic aperture radar (SAR) system in space, formed by the twin X-band satellites TerraSAR-X (TSX) and TanDEM-X (TDX). The primary objective of the mission is the generation of a worldwide, consistent, timely, and high-precision DEM [2]. The two satellites fly in a closely controlled formation with typical distances between 250 and $500 \mathrm{~m}$ and thereby act as a large single-pass radar interferometer with the opportunity of flexible baseline selection for the demonstration of innovative SAR techniques and applications. In September 2014, TanDEM-X has completed the global acquisition of the
Earth's land masses in bistatic configuration, which means that either TSX or TDX transmits the radar signal and both satellites act as receivers. For the global DEM acquisition the horizontal polarization channel $(\mathrm{HH})$ has been chosen for the transmission and reception of the radar signal, as it provides a slightly higher performance within the TanDEM$\mathrm{X}$ system [3]. Two global coverages have been completed by employing different baselines and slightly displaced beams in order to improve the overall quality and to keep it uniform over range [2]. Very good and reproducible performance has been verified for most of the land masses [4]. Areas showing critical performance such as forests, rugged terrain, as well as desert regions have been additionally reacquired with optimized imaging geometry during the whole mission duration, in order to help and ease the unwrapping process, to minimize the occurrence of gaps in the final DEM, and to improve the global mission performance [5], [6], [7]. In this paper, we focus our attention on the specific case of sandy desert areas: in these typically inaccessible and inhospitable environments, which represent about $5 \%$ of the Earth's land surface, remote sensing data are of fundamental importance, since they are able to provide the perspective required for the knowledge of aridland geology and resources, such as hydrocarbon reservoirs, evaporites, and other mineral deposits, as well as human artifacts preserved for centuries by the arid climate. As an example, the availability of precise height profiles of desert areas can be very useful for the exploration of oil fields by means of seismic tests [8], [9]. However, the quality of radar remote sensing surveys over sandy regions may be strongly affected, mainly due to the weak backscattering properties of the sand [10]. In the microwave spectrum dry materials, such as sand particles, reflect the incident electromagnetic radiation randomly, which results in a loss of energy [11]. On the other hand, the penetration capability of microwaves is defined by both the imaging parameters (e.g. the radar wavelength, the antenna gain, the transmitted power, and the incidence angle), as well as the scattering characteristics of the imaged scene, such as the dielectric and geometric properties [12]. Several studies have demonstrated that lowfrequency microwaves are able to penetrate dry sand up to a depth of several meters [11], [13], [14], [15]. SRTM had problems with deserts measured in C-band, and corrections and data interpolation were applied to fill gaps in the official version of the DEM [16]. Recently, investigations aiming at determining the capabilities of TanDEM-X bistatic data for possible archaeological applications have shown that X-band 


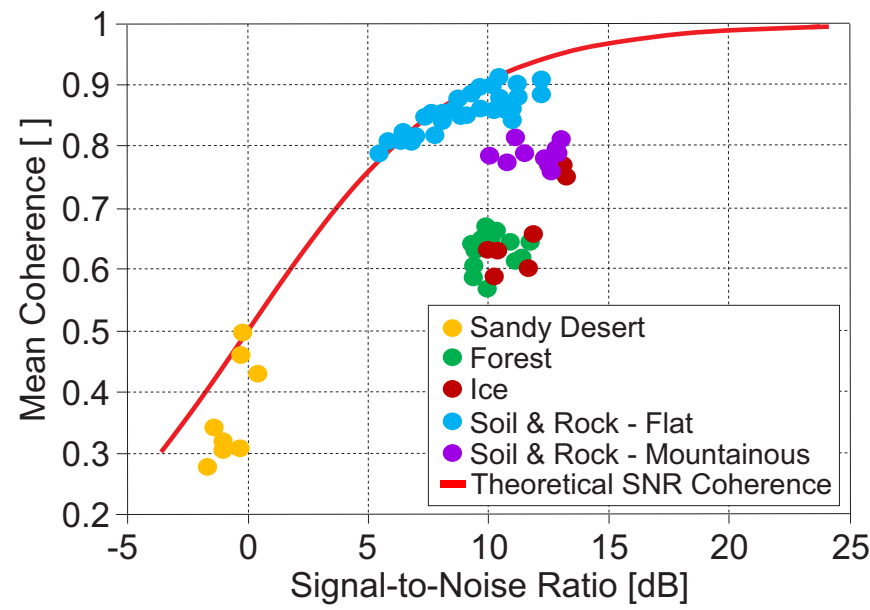

Fig. 1. Interferometric coherence of TanDEM-X acquisitions plotted over signal-to-noise ratio (SNR). The red line indicates the theoretical SNR coherence, as defined in (2).

waves have a limited penetration depth of about $20-30 \mathrm{~cm}$ in dry desert soil, which makes high-frequency microwave radar imaging suitable for the characterization of dry sand surfaces, and, at the most, for shallow-buried archaeological remains [17]. However, for the incidence angles employed in the TanDEM-X mission (nominally greater than $30^{\circ}$ ) the quality of the TanDEM-X interferometric products over sandy desert areas is sometimes severely affected. This article presents a detailed performance analysis of TanDEM-X data over sandy areas and is organized as follows: in the next section typical SAR and InSAR quality descriptors are evaluated on TanDEM-X data acquired over sandy areas. In Section III, the test area of the Gobi Desert is investigated in detail, where the presence of rugged topography additionally degrades the poor performance caused by the weak backscattering of sand. Furthermore, possible alternative processing strategies aiming at improving the quality of the interferometric products are described. Based on the presented findings, the reacquisition of sandy areas with an optimized geometry is described in Section IV, and the resulting improvement of the TanDEM-X data quality is discussed.

\section{TANDEM-X PERFORMANCE OVER SANDY AREAS}

One of the key parameters to evaluate the quality of remote sensing imaging is the signal-to-noise ratio (SNR), which describes how much a signal has been corrupted by noise. From a SAR image, the SNR is computed as follows:

$$
\mathrm{SNR}=\frac{\sigma_{0}\left(\theta_{\mathrm{i}}\right)}{\operatorname{NESZ}\left(\theta_{\mathrm{i}}\right)}
$$

where $\sigma_{0}$ is the backscatter coefficient, and NESZ (noise equivalent sigma zero) describes the influence of thermal noise contributions. On TSX and TDX, the NESZ is estimated by means of receive-only pulses, which are acquired at the beginning and at the end of each data take. Both the $\sigma_{0}$ and the NESZ are a function of the local incidence angle $\theta_{\mathrm{i}}$. In interferometric SAR applications, the finite sensitivity of the receiving system is a significant error source which directly affects the interferometric coherence $\gamma$ between the two interferometric channels. The coherence represents the normalized complex correlation coefficient between the master and slave acquisitions and gives information about the amount of noise in the interferogram. Several error sources may cause decorrelation in TanDEM-X data [3]. For a bistatic SAR acquisition of TanDEM-X, the coherence loss due to a finite system sensitivity $\gamma_{\mathrm{SNR}}$ is given by [18]

$$
\gamma_{\mathrm{SNR}}=\frac{1}{\sqrt{1+\mathrm{SNR}_{\mathrm{TSX}}^{-1}} \cdot \sqrt{1+\mathrm{SNR}_{\mathrm{TDX}}^{-1}}},
$$

where $\mathrm{SNR}_{\mathrm{TSX}}$ and $\mathrm{SNR}_{\mathrm{TDX}}$ are the signal-to-noise ratios for the TSX and the TDX satellites, respectively. In order to investigate the effects of SNR on the interferometric performance of TanDEM-X, single-pass bistatic acquisitions over areas showing different vegetation and soil characteristics have been analyzed. The observed difference in terms of SNR between TSX and TDX is quite small (usually less than $1 \mathrm{~dB}$ ) and, therefore, it can be reasonably assumed that $\mathrm{SNR}_{\mathrm{TSX}}=\mathrm{SNR}_{\mathrm{TDX}}=\mathrm{SNR}$. The interferometric coherence over SNR is depicted in Fig. 1 for bistatic TanDEM-X scenes acquired over different land classes. A scene typically extends by $30 \mathrm{~km}$ in range and $50 \mathrm{~km}$ in azimuth and, for this analysis, the mean values per scene have been considered. Empty brackets are used in the axis label to indicate that the coherence is a dimensionless quantity. Soil and rock regions characterized by flat topography (marked in light blue) typically show better performance $(\gamma>0.7)$ than areas covered by dense forest (green) or ice (brown), where coherence losses are predominantly due to the existence of volumetric scattering which increases the interferometric phase noise [19]. Over regions characterized by mountainous terrain (violet), shadow and layover effects additionally degrade the coherence. For most of the land cover types, however, an SNR higher than 5 $\mathrm{dB}$ is observed. A stable interferometric performance is mainly obtained with a coherence greater than 0.6, which typically assures a sufficient phase unwrapping quality [5]. The red line in the figure indicates the theoretical SNR coherence as defined in (2) and proves the presence of additional decorrelation sources.

On the other hand, it is evident that the performance over sandy deserts (in orange) is strongly affected by the weak power of the backscattered signal from sand. The data takes have been acquired over the desert of Saudi Arabia, and for SNR values around $0 \mathrm{~dB}$ a coherence above 0.5 is seldom observed, which exactly agrees to (2). This is because the electromagnetic energy impinging the sand surface is mainly reflected in the specular direction as well as absorbed by the dry sand layer. Therefore, only a small fraction of the signal is backscattered to the sensor and a poor interferometric coherence (SNR decorrelation) is consequently observed. In particular, it can be noticed that, for values around and below $0 \mathrm{~dB}$, the SNR appears to be slightly overestimated. For such low backscatter levels, indeed, the received signal power is of the same order of magnitude as the system noise, and the SNR estimate is consequently biased. Other error sources, such as coregistration errors, block adaptive quantization, geomet- 


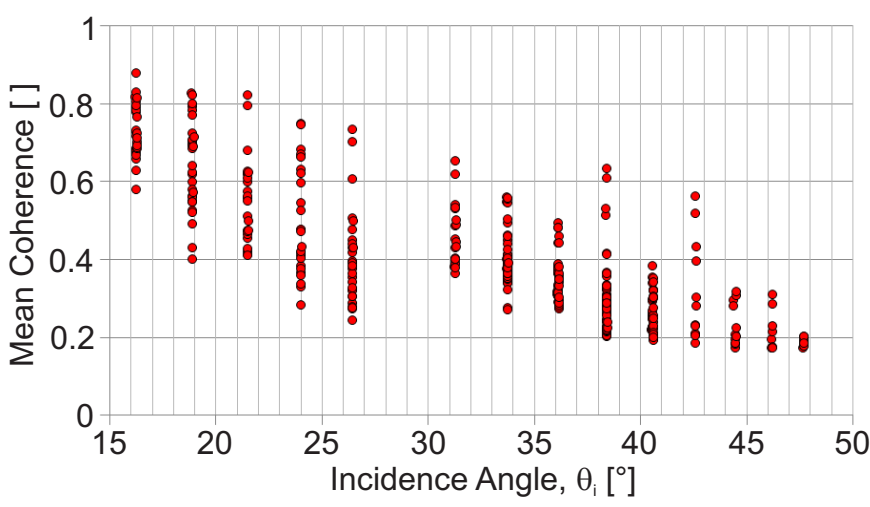

Fig. 2. Mean coherence of individual scenes as a function of the incidence angle evaluated for bistatic acquisitions over the Saudi Arabia desert.

ric decorrelation, and ambiguities, may cause an additional coherence loss in the TanDEM-X interferometric data [20], [21]. In most cases, sandy deserts are characterized by a homogeneous backscatter distribution as well as by low and gentle sand dunes, and can be well approximated by distributed targets. According to this, the corresponding coherence loss due to range and azimuth ambiguities $\gamma_{\mathrm{Amb}}$ will be lower than $3 \%$ (i.e. $\gamma_{\mathrm{Amb}}>0.97$ ) [2], [3]. Analogously, quantization errors cause a decorrelation $\gamma_{\text {Quant }}$ which is in the range between 0.97 and 0.98 [21]. The interferometric baseline employed for the bistatic data takes depicted in Fig. 1 varies typically between 80 and $250 \mathrm{~m}$. This could cause a baseline decorrelation, which is for the nominal incident angles below $10 \%$. Spectral filtering is, however, employed in TanDEM-X, which removes this small baseline decorrelation component for flat scenes. The few values which are slightly above the red curve can be due to inaccurate estimations of the noise profiles.

During the whole TanDEM-X mission duration, dedicated bistatic data takes over sandy areas have been acquired covering a wide range of incidence angles. The mean coherence against incidence angle is shown in Fig. 2, for data takes acquired over the desert of Saudi Arabia. The incidence angles employed for the TanDEM-X nominal mission operation range between $29^{\circ}$ and $49^{\circ}$, and a poor coherence mostly below 0.5 is observed. All along the paper the corresponding beams will be referred to as "nominal beams". As an example, the coherence maps for two bistatic scenes over the Taklamakan desert (China) are shown in Fig. 3. For the image on the left side, the incidence angle is about $48^{\circ}$, for the one on the right side it is $16^{\circ}$. The SNR is about $10 \mathrm{~dB}$ higher in the right image, and the mean coherence goes from 0.52 to 0.84 . The performance gain obtained when using steeper incidence angles is due to an increase of the backscattered power but also, at the same time, to an improvement of the system sensitivity, which is proportional to the third power of the slant range [2]. In particular, when acquiring the same scene with steeper angles, the amount of power absorbed by the sand surface remains approximately the same, whereas the fraction of the signal reflected back to the sensor is maximized. The combination of both effects results in an
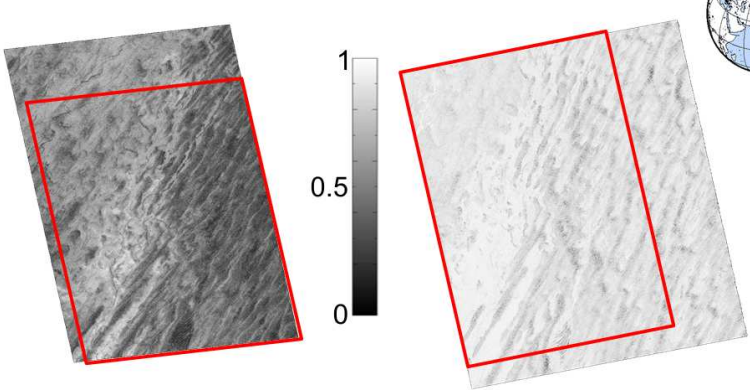

Fig. 3. TanDEM-X coherence maps over Taklamakan desert (China); (left) $\mathrm{HH}$ polarization, $\theta_{i}: 48^{\circ}$, mean coherence: 0.52 ; (right) $\mathrm{HH}$ polarization, $\theta_{i}$ : $16^{\circ}$, mean coherence: 0.84 . The area common to the two acquisitions is highlighted in red.

increase up to $15 \mathrm{~dB}$ in terms of SNR. The influence of each contribution can be seen in Fig. 4, where the predicted NESZ profiles [2] are depicted in black. For the evaluation of the backscatter coefficient $\sigma_{0}$ over desert different approaches have been considered. First, the backscatter coefficient is estimated directly from the SAR amplitude, and the obtained $50 \%$ occurrence levels over a desert area in Mauritania are depicted in red. For incidence angles higher than $35^{\circ}$ the measured $\sigma_{0}$ seems to saturate, which can be explained with the fact that, for shallow incidence angles, the backscatter goes below the system sensitivity [22], [23]. In order to estimate the $\sigma_{0}$ from such low backscatter areas more accurately, four test acquisitions with a reduced range bandwidth set to $10 \mathrm{MHz}$ have been additionally commanded. In this way, a proportional improvement of the system sensitivity of $10 \mathrm{~dB}$ can be achieved (for nominal TanDEM-X acquisitions 100 $\mathrm{MHz}$ bandwidth is selected). The corresponding backscatter estimates are indicated by the four blue circles. A good agreement between the measured SAR amplitudes is observed for steep incidence angles, while for shallow angles smaller (that is, less biased and therefore more realistic) values in the range between -30 and $-27 \mathrm{~dB}$ have been measured, as a consequence of the improved system sensitivity at 10 $\mathrm{MHz}$ bandwidth. Another approach for the evaluation of the backscatter coefficient from InSAR data exploits the estimated interferometric coherence $\gamma$. An SNR map can be derived by inversion of (2). For this, it is assumed that the limited receiver sensitivity represents the only error source (i.e. $\gamma \approx \gamma_{\mathrm{SNR}}$ ), which is a plausible hypothesis for this scenario. Then, the $\sigma_{0}$ is estimated from (1) as

$$
\sigma_{0}=\operatorname{NESZ} \frac{\gamma}{1-\gamma}
$$

and the corresponding 50\% occurrence levels are depicted in green in Fig. 4 for the $100 \mathrm{MHz}$ acquisitions. The two (red and green) curves agree quite well in the range between about $17^{\circ}$ and $35^{\circ}$, whereas the coherence-derived $\sigma_{0}$ gives more consistent estimates of the backscatter coefficient for higher incidence angles. On the other hand, a discrepancy of $\sigma_{0}$ of about $5 \mathrm{~dB}$ is observed for the steepest beam, with respect to the first approach. This is presumably due to the fact that 
NESZ and Sigma Nought (for 50\%) over Mauritania Desert

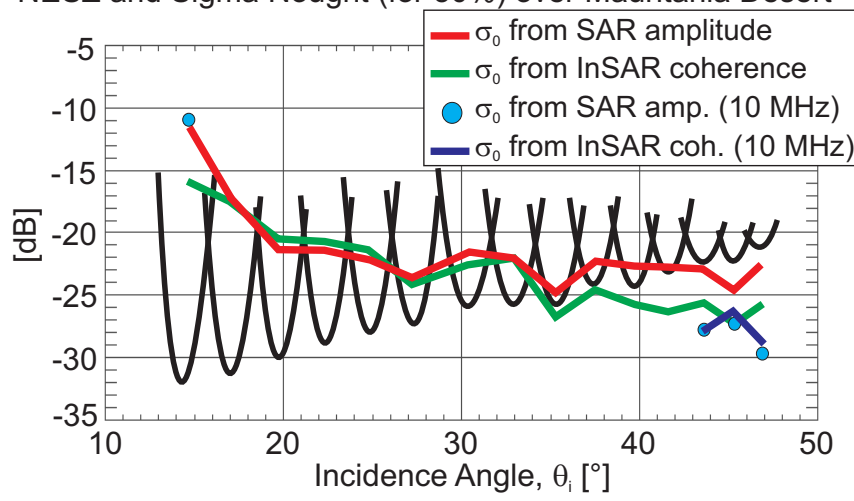

Fig. 4. Predicted NESZ for untapered stripmap beams (in black) and scattering coefficients for $50 \%$ occurrence levels estimated over a desert area in Mauritania from the SAR amplitude acquired with full range bandwidth of $100 \mathrm{MHz}$ (red), and from the interferometric coherence (green), as a function of the incidence angle. Light blue circles indicate the backscatter coefficient estimated from four data takes commanded with reduced range bandwidth (10 $\mathrm{MHz}$ ), whereas the $\sigma_{0}$ derived from the corresponding interferometric coherence are depicted with the dark blue line.

for small incidence angles other decorrelation sources become dominant in the coherence estimation, such as geometrical distortions. The same comparison has been made for the acquisitions with reduced range bandwidth $(10 \mathrm{MHz}){ }^{1}$ The corresponding coherence-derived backscatter coefficients are depicted by the dark blue line, and a good agreement between the two estimation approaches can be verified. It is worth restating that these values cannot be directly compared with the data takes with full $100 \mathrm{MHz}$ bandwidth, which have been acquired at different times: sandy areas are quite unstable over time, and significant changes can be observed in repeated Xband SAR acquisitions, as shown in the following.

In Fig. 5, the coherence versus the height of ambiguity is plotted for repeated bistatic data takes acquired over the Saudi Arabia desert. The height of ambiguity (HoA) is the height difference corresponding to a complete $2 \pi$ cycle of the interferometric phase and is expressed as

$$
\mathrm{HoA}=\frac{\lambda r \sin \left(\theta_{\mathrm{i}}\right)}{B_{\perp}},
$$

being $\lambda$ the radar wavelength, $r$ the slant range, $\theta_{\mathrm{i}}$ the incidence angle, and $B_{\perp}$ the baseline perpendicular to the line of sight. The different HoAs in Fig. 5 are due to changes of the satellite formation over time [2]. From Fig. 5, no systematic influence of the height of ambiguity on the interferometric coherence can be found (for a given incidence angle), which is due to the limited penetration capability of $\mathrm{X}$-band waves. Indeed, the volume scattering contribution from sand particles within the random medium at millimeter [22] to centimeter [24] wave frequencies is generated by a sand layer few tens of centimeters deep. This leads to negligible volume decorrelation effects (in comparison to forested areas or ice regions, as shown in Fig. 1) for heights of ambiguity typical

\footnotetext{
${ }^{1}$ Note that the acquisition with the steep incident angle has not been considered since it would cause a too large spectral shift if compared to the narrow range bandwidth.
}

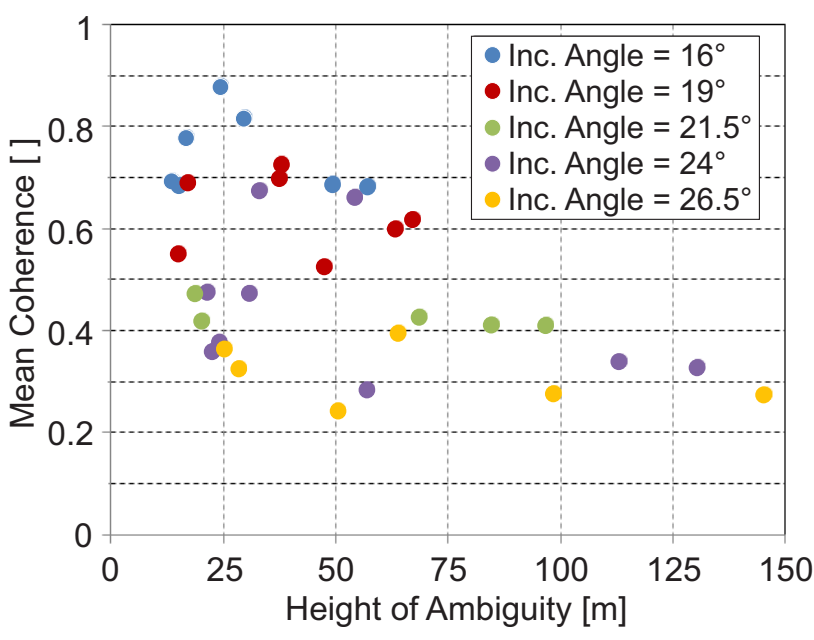

Fig. 5. Mean coherence versus height of ambiguity for different incidence angles, depicted with different colors for bistatic acquisitions over the Saudi Arabia desert.

for TanDEM-X (in the range between 30 and $60 \mathrm{~m} \mathrm{[3]).}$ Given a certain baseline, smaller HoAs are obtained for steeper incidence angles, as defined in (4). Moreover, a rather variable, unstable performance is observed for a given beam, which reflects a strong variability in the imaged scene in terms of radar backscatter. For test sites acquired at different times, SNR differences up to $8 \mathrm{~dB}$ were observed, which are due to changes in the sand distribution, in the roughness conditions, as well as due to atmospheric effects [25], [26]. ${ }^{2}$ In Fig. 6 the same coherence values are plotted as a function of the corresponding SNR estimates. It can be verified - once more that the power backscattered to the receive antenna is the most critical quantity for defining SAR and InSAR performance over sandy areas, and that it is mainly influenced by the used incidence angle. However, one can notice that for the steepest incidence angle (in blue) geometrical decorrelation becomes significant (see also Fig. 7). The negligible contribution of volume scattering has been furthermore verified by comparing the scattered power of the cross-polar (HV) channel with the co-polar $(\mathrm{HH})$ one for repeated acquisitions over test sites showing different land cover characteristics, as depicted in Table I: unlike forest or ice regions, sand shows negligible depolarization effects (about $9 \mathrm{~dB}$ smaller), which confirms the fact that basically sand is "seen" by X-band waves as a surface. On the other hand, no systematic and relevant difference between the $\mathrm{HH}$ and VV channels was observed in the considered SAR/InSAR quality descriptors.

It is known that the acquisition geometry (as the interferometric baseline and the incidence angle) employed for InSAR surveys may have a significant effect on the interferometric data quality due to varying geometrical distortions. They are caused by the so-called baseline decorrelation, as well as by shadow, foreshortening, and layover effects. In order to mitigate the baseline decorrelation [27], the operational Integrated TanDEM-X Processor (ITP) performs a range spectral

\footnotetext{
${ }^{2}$ Such temporal changes in the imaged scene represent an additional, dramatic limitation for a repeat-pass interferometer operating at centimeter wavelength, but are overcome by a bistatic system such as TanDEM-X.
} 


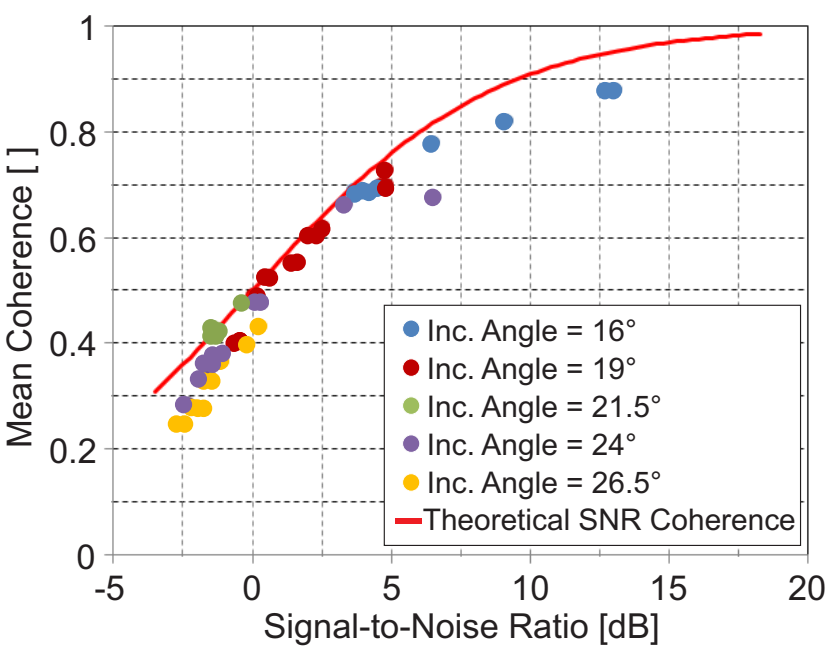

Fig. 6. Mean coherence over signal-to-noise ratio (SNR) for the same TanDEM-X bistatic data takes over the Saudi Arabia desert as in Fig. 5. The red line indicates the theoretical SNR coherence, according to (2).

filtering of both channels to a common frequency band. This is done by employing precise orbit and baseline information together with the mean scene height, assuming a flat scene. Therefore, baseline decorrelation may still affect the resulting TanDEM-X DEM over regions with rugged topography. For a bistatic TanDEM-X interferogram the geometrical decorrelation $\gamma_{\text {Geom }}$ can be estimated by

$$
\gamma_{\text {Geom }} \cong \frac{\gamma}{\gamma_{\mathrm{SNR}} \cdot \gamma_{\text {Quant }} \cdot \gamma_{\mathrm{Amb}} \cdot \gamma_{\mathrm{Vol}}},
$$

where $\gamma$ is the mean coherence and $\gamma_{\mathrm{SNR}}$ is obtained from (2). From this, a coherence loss of 5\% due to quantization errors and ambiguities is considered, i.e. $\gamma_{\text {Quant }} \cdot \gamma_{\text {Amb }} \cong 0.95$ [3]. It has previously been shown that possible decorrelation caused by the presence of volume scattering can be reasonably neglected over sandy areas at X-band, i.e. $\gamma_{\text {Vol }}=1$. In Fig. 7 , the geometrical decorrelation $\gamma_{\text {Geom }}$ is plotted against the incidence angle for several bistatic scenes acquired over two desert areas. The test area in the Taklamakan desert (in red) is characterized by low and gentle dunes, typically of few tens of meters height, and a geometric decorrelation lower than $5 \%$ is observed even for very steep incidence angles where a small local slope may cause a comparably large spectral shift. On the other hand, the Gobi desert shows a rugged topography with steep dunes that reach heights of several hundreds of meters, which challenges the performance of the unwrapping process (see also next section). For this, a high decorrelation of

TABLE I

DEPOLARIZATION EFFECTS (MEASURED AS THE RATIO OF THE CROSS-POLAR HV AND THE CO-POLAR HH CHANNEL) FOR DIFFERENT LAND COVER TYPES.

\begin{tabular}{|c|c|c|}
\hline Test Site & Land Cover & $\frac{\left\langle|H V|^{2}\right\rangle}{\left\langle|H H|^{2}\right\rangle}$ [dB] \\
\hline Amazon Forest (Brazil) & Rainforest & -6.5 \\
\hline Borneo Forest (Indonesia) & Hilly Tropical Forest & -6.7 \\
\hline Greenland & Ice and Snow & -7.4 \\
\hline Taklamakan (China) & Sandy Desert & $\mathbf{- 1 5 . 5}$ \\
\hline
\end{tabular}

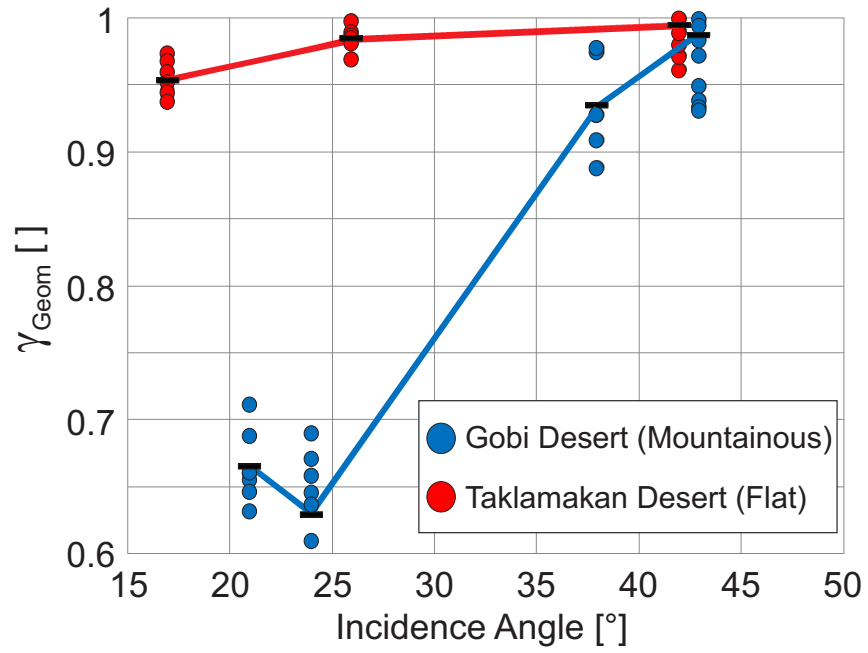

Fig. 7. Geometrical decorrelation estimated for bistatic scenes acquired over two desert regions with different incidence angles. The test area in the Taklamakan desert (in red) is characterized by a flat topography, and a mean geometrical decorrelation lower than $5 \%$ is observed for very steep incidence angles. On the other hand, for the Gobi desert (in blue), a mean geometrical decorrelation of about 0.65 is obtained for incidence angles of about $20^{\circ}-25^{\circ}$. The impact of geometrical distortions becomes less critical for both test areas, if shallow incidence angles larger than $40^{\circ}$ are employed.

about 0.65 is observed for incidence angles of about $20^{\circ}-25^{\circ}$. As expected, geometrical decorrelation becomes less critical for both test areas, if incidence angles larger than $40^{\circ}$ are employed (of course, for shallow angles shadow effects may become dominant, together with the low backscattered signal).

\section{Processing of ACQUisitions OVER SANDy AREAS With TAnDEM-X: The Gobi Test AREA}

The Gobi is a large desert region in Asia. Its sandy basins are located between north China and southern Mongolia (the so-called Badain Jaran desert, latitude $\in\left[37^{\circ}, 41^{\circ}\right]$, longitude $\left.\in\left[100^{\circ}, 106^{\circ}\right]\right)$. Sandy deserts are typically covered with dunes, which are asymmetrical mounds showing a gentle slope in the upwind direction and steep slope on the downwind side. Dunes may be characterized by different heights, slopes, and orientations. They migrate by erosion of sand caused by wind (saltation) on the gentle upwind slope, and deposition and sliding on the slip face, and thus are cross-bedded deposits. In particular, the Badain Jaran desert is predominated by the so-called megadunes [28]. Similarly to the barchanoid dunes, they are crescent-shaped dunes with the points of the crescents pointing in the upwind direction (with gentle slopes of $15^{\circ}$ or less), and a curved slip face on the downwind side of the dune (with steep slopes of about $30^{\circ}$ ) [29]. They form in areas where there is a hard ground surface, a moderate supply of sand, and a constant wind direction, and can reach heights up to several hundreds of meters. An optical image of the test area under investigation is depicted in Fig. 8 (scene center latitude/longitude $\left[42^{\circ}, 100^{\circ}\right]$ ) and has been covered by several test data takes in different acquisition configurations: ascending and descending orbits, steep and shallow incidence angles (all in right-looking geometry, which is the TanDEM$\mathrm{X}$ nominal operation mode). The area is located at a mean 


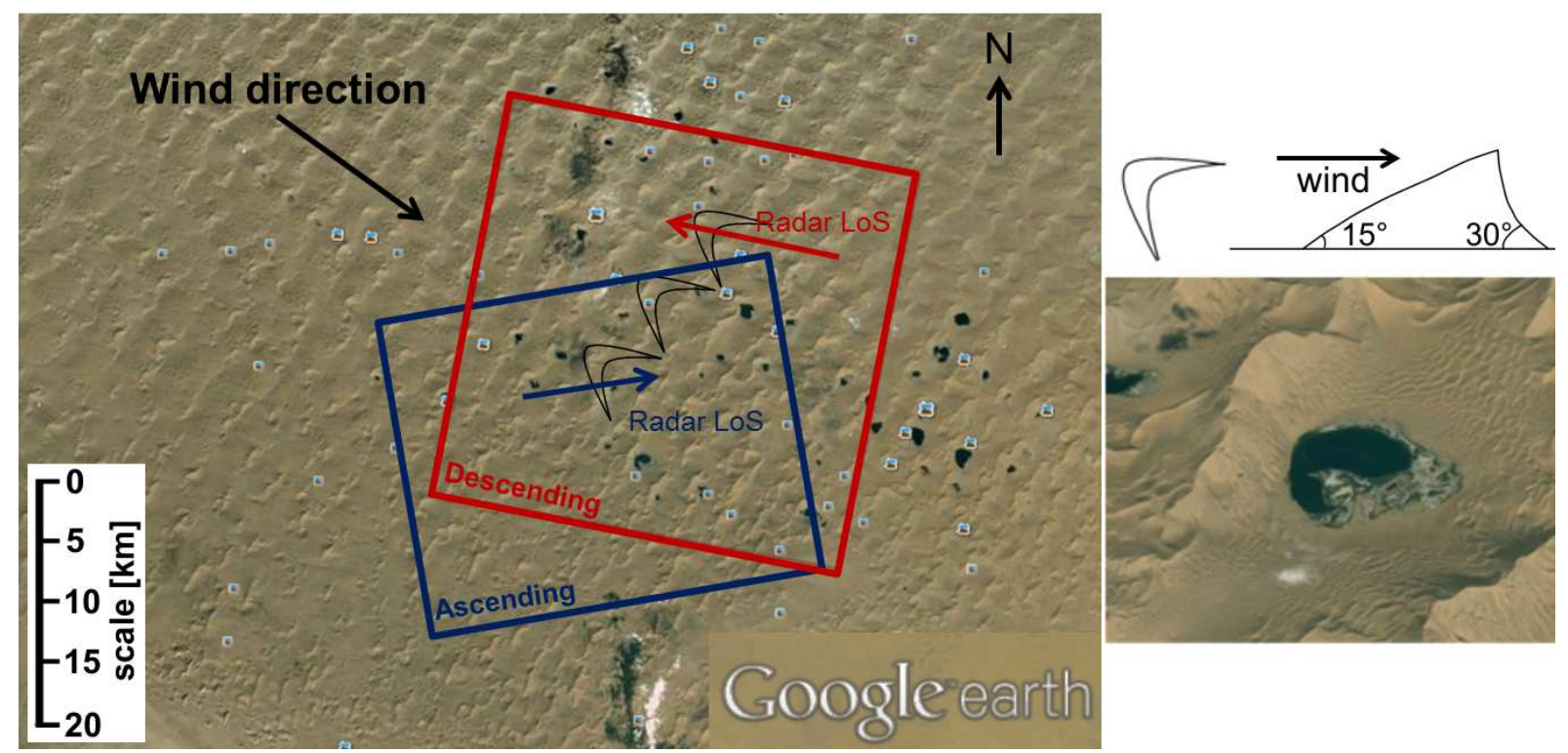

Fig. 8. (Left) Optical view (Google Earth image) of the selected test site over the Gobi desert. The area extends by about $65 \mathrm{~km}$ in latitude and by $90 \mathrm{~km}$ in longitude direction, and is characterized by the presence of megadunes of about $300 \mathrm{~m}$ height (the mean altitude is of about $1200 \mathrm{~m}$ ), whose orientation is outlined in the figure. The wind blows from North-West. Exploiting different orbits, TanDEM-X is able to acquire the same area in ascending (blue polygon) or descending (in red) direction. (Right) A crop of the optical image: here a single megadune is located left from a water oasis. The crescent-shaped dune orientation is also sketched.

altitude of approximately $1200 \mathrm{~m}$ and is characterized by the presence of dunes with large topography (about $300 \mathrm{~m}$ height difference between the top and the bottom), where the sides with gentle slopes are oriented towards the direction of the wind. An example is shown in the crop on the right hand side of Fig. 8, where a megadune stands out left to a water oasis. The Gobi desert represents a particularly difficult scenario, since the weak backscatter from sand is combined with a rugged dunes topography, which challenges the performance of the unwrapping process. Therefore, a careful selection of the acquisition geometry is required. In Fig. 9 the SAR amplitude (Fig. 9 (a), (b), (c), (d)) and the corresponding interferometric coherence (Fig. 9 (e), (f), (g), (h)) for the crop depicted in Fig. 8 is shown, for data takes acquired from different geometries. Areas with low coherence can be observed particularly in Fig. 9 (f), which corresponds to the acquisition in descending geometry with steep incidence angle $\left(24^{\circ}\right)$. Indeed, if descending geometry is selected with a steep incidence angle, the steep side of the dune faces the radar line of sight causing dominant geometrical distortion [27], [30], [31], such as foreshortening and layover, as it can be noticed also from Fig. 9 (b). The acquisition can be optimized if ascending geometry with a shallow incidence angle of $38^{\circ}$ is selected (Fig. 9 (c) and (g)). In this way, the image is obviously more affected by shadow, but the gentle side of the dune is observed by the radar line of sight, which minimizes the overall geometrical distortions (Fig. 9 (c)), resulting in a higher and more homogeneous coherence, as shown in Fig. 9 (g). Similarly, the ascending acquisition with steep angle $\left(21^{\circ}\right.$, Fig. 9 (a) and (e)) shows strong inhomogeneities in the backscatter and consequently in the coherence distribution. In this case, the steep face of the dune slope clearly lies in the shadow region. Finally, Fig. 9 (d) and (h) show the amplitude and coherence, respectively, for the acquisition performed in descending orbit with shallow incidence angle $\left(40^{\circ}\right)$. The coherence distribution looks more homogeneous and almost complementary to the one in Fig. 9 (g), as it is evident when looking at the two sides of the dune located left from the water oasis. The maximization of the signal-to-noise-ratio and/or of the coherence is not the only aspect to be considered. The performance of the phase unwrapping operation is also a critical aspect and plays a key role in determining the quality of a DEM. A comparison of the unwrapped TanDEM$\mathrm{X}$ phase with a simulated phase from an SRTM DEM is given as an indicator of the phase unwrapping performance. The (single-baseline) Minimum Cost Flow (MCF) [32] algorithm embedded in the Integrated TanDEM-X Processor (ITP) [33] has been used. It is worthy to mention that the ITP operationally uses a dual-baseline approach for the unwrapping of the phase [34]. However, this analysis was restricted to the use of a single-baseline phase unwrapping. Fig. 10 shows a comparison of the phase unwrapping performance for two acquisition geometries for the previous scenarios of Gobi (whole scene). Green color indicates agreement between the phase measurements derived from TanDEM-X and a simulated phase obtained using precise orbit information and an SRTM DEM. On the other hand, red and blue correspond to positive or negative discrepancies by more than half of a phase cycle, which indicate the occurrence of unwrapping errors. A poor performance with many unwrapping errors can be noticed for the acquisition with steep incidence angle (left-hand side of Fig. 10), due to the presence of layover and shadow areas, whereas the acquisition with shallow incidence angle (righthand side of Fig. 10) shows, in general, a satisfactory phase unwrapping quality. There are still some areas in disagreement, but it can be clearly seen that they correspond to physical 


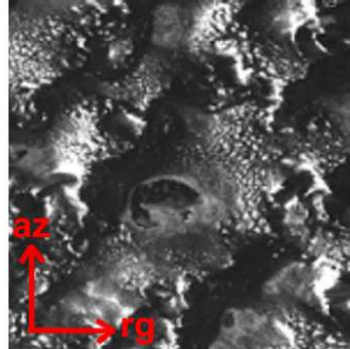

(a) Asc., steep $\left(\theta_{i}=21^{\circ}\right)$

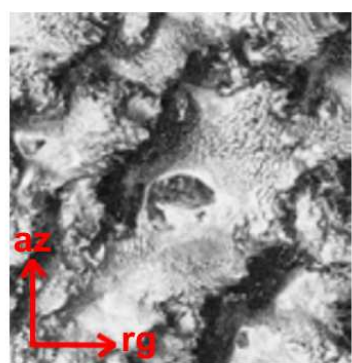

(e) Asc., steep $\left(\theta_{i}=21^{\circ}\right)$

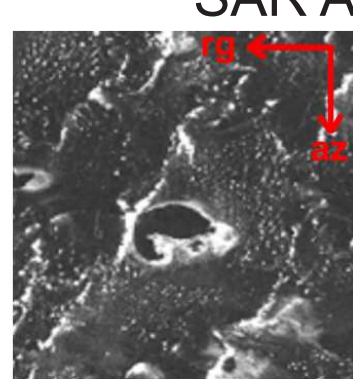

(b) Desc., steep $\left(\theta_{i}=24^{\circ}\right)$

Coherence

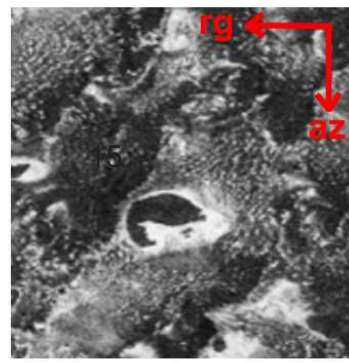

(f) Desc., steep $\left(\theta_{i}=24^{\circ}\right)$

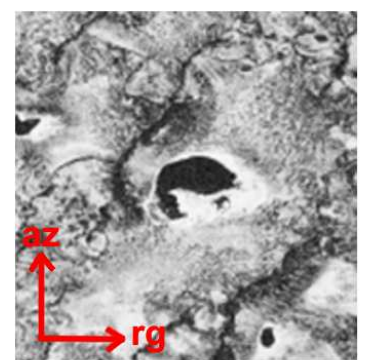

(g) Asc., flat $\left(\theta_{i}=38^{\circ}\right)$

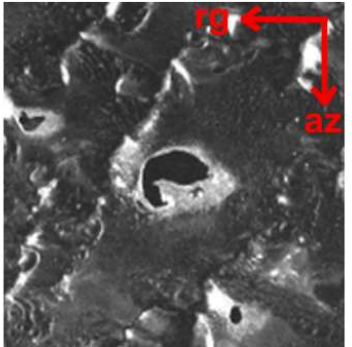

(d) Desc., flat $\left(\theta_{i}=40^{\circ}\right)$

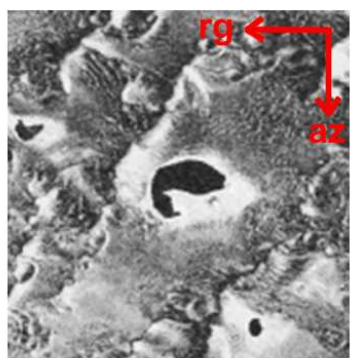

(h) Desc., flat $\left(\theta_{i}=40^{\circ}\right)$

Fig. 9. Comparison of the amplitude images (a), (b), (c), (d) and the coherence maps (e), (f), (g), (h) for the crop of the radar images in Fig. 8, acquired from different orbit directions (Asc./Desc. stand for ascending/descending, respectively) and incidence angles. Dark (bright) colors represent low (high) backscatter and coherence. Azimuth (az) and range (rg) are indicated on the lower right.
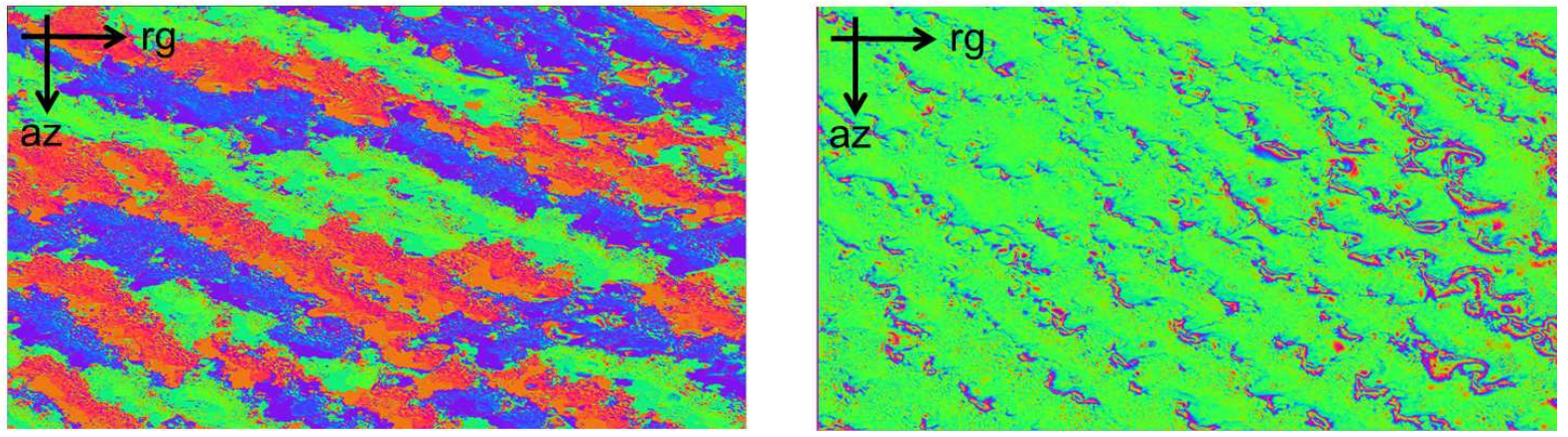

Fig. 10. Comparison of the phase unwrapping performance of TanDEM-X with reference to the SRTM simulated phase over Gobi desert. Red and blue indicate a positive or negative discrepancy by more than half of the height of ambiguity, whereas green indicates agreement between the two phase measurements (Left) Ascending steep incidence angle $\left(21.4^{\circ}\right)$. (Right) Ascending shallow incidence angle $\left(38^{\circ}\right)$. Azimuth (az) and range (rg) are indicated in the upper left of each residual phase image.

features probably due to temporal changes (e.g. dunes migration). Another experiment has been performed, where different spatial multilooking filters, as available in the literature, have been explored. An acquisition in descending geometry with steep incidence angle $\left(24^{\circ}\right)$ and a height of ambiguity of 88 $\mathrm{m}$ has been selected (which should be sufficiently large for the present topography). While sufficiently high backscatter levels are expected, this acquisition offers nevertheless a difficult scenario to suitably test the unwrapping quality, due to the resulting local incidence angle (as also discussed in Fig. 9). The applied multilooking approaches are as follows:

- Nominal TanDEM-X multilooking filter employing a $3 \times 7$ boxcar, applied by the operational ITP [33],

- Gaussian multilooking filter [35] of size $15 \times 35$ pixels,
- Adaptive directional fringe filter based on [36], which averages the complex interferogram in the perpendicular direction to the maximum phase gradient,

- Intensity-Driven Adaptive-Neighborhood (IDAN) filter [37], which identifies for each pixel an adaptive neighborhood, using region growing techniques, with similar intensity statistics.

Fig. 11 shows a comparison of the results of the phase unwrapping performance with reference to the SRTM simulated phase for each filter. It can be seen that all applied multilooking approaches fail, and the reason for this is the non-suitability of the acquisition geometry, which introduces important geometric distortions, as layover and shadow. The outcome of the present investigations makes clear the necessity for alternative 
(a) Nominal TanDEM-X Multilooking

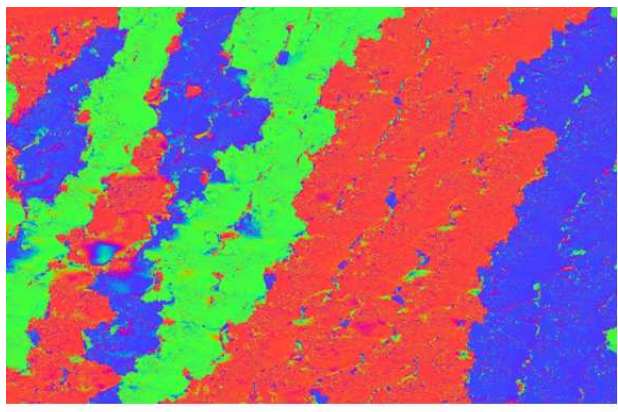

(c) Adaptive Filter

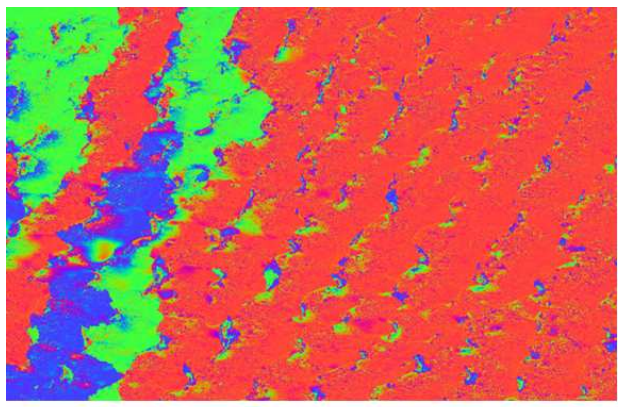

(b) Gaussian Multilooking $15 \times 35$

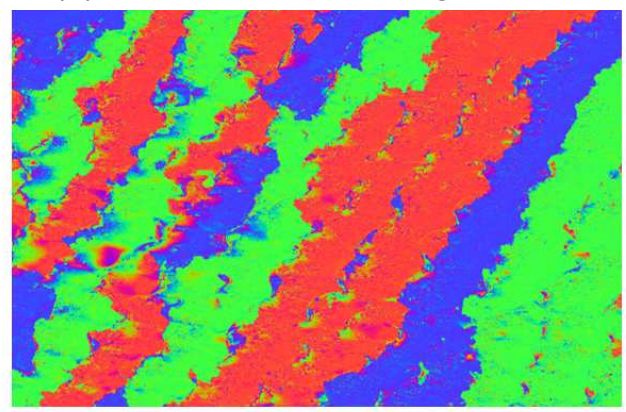

(d) IDAN Filter

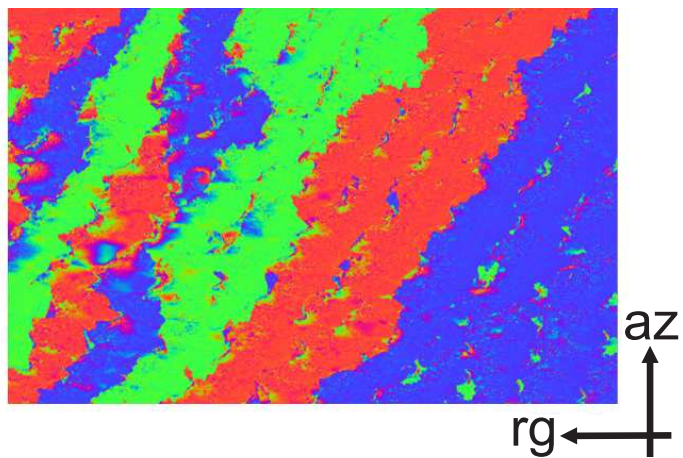

Fig. 11. Comparison of the TanDEM-X phase unwrapping performance to the SRTM simulated phase over Gobi desert. (a) Nominal TanDEM-X multilooking filter employing a $3 \times 7$ boxcar. (b) Employment of a Gaussian multilooking of $15 \times 35$ pixels. (c) Adaptive directional fringe filter. (d) IDAN filter. Azimuth (az) and range (rg) are indicated, too.

acquisition configurations, since a careful acquisition planning is of paramount importance to map these difficult areas. In particular, those sand regions characterized by rugged dunes topography have been additionally reacquired with opposite viewing geometry and shallow incidence angles, between $29^{\circ}$ and $49^{\circ}$, in order to mitigate the occurrence of geometrical distortions and to improve the overall DEM quality.

\section{OPtimized ACQuisition AND DEM Performance IMPROVEMENT}

In the previous sections we have verified that the specific acquisition geometry plays a key-role in determining the quality of interferometric SAR products for sandy desert regions. Such areas have been identified as homogeneous and incoherent areas [3]. The corresponding regions, covering about $5 \%$ of the Earth's landmass, are highlighted in red in Fig. 12, [38]. A dedicated reacquisition campaign started in mid 2013 by employing steep incidence angles in the range between $14^{\circ}$ and $30^{\circ}$ (with $\mathrm{HH}$ polarization and range bandwidth of $100 \mathrm{MHz}$ ) in order to minimize the performance loss and to improve the overall DEM quality [7]. This has been possible by exploiting the high flexibility of TanDEM-X, which allows to acquire, for a given flight direction, the same ground coordinates from different orbit positions (i.e. incidence angles), as shown in Fig. 13. At small latitudes (i.e. close to the equator), however, the ground range separation between contiguous orbits, which is qualitatively represented by the distance $d$ in Fig. 13, increases. This implies that the set of incidence angles available to image a certain point on ground is reduced. In particular at the equator, areas which are nominally covered with incidence angles between $29^{\circ}$ and $36^{\circ}$ cannot be acquired with steeper angles, as depicted in Fig. 13. On the other hand, an increasing ground swath overlap is exploited at higher latitudes. In order to keep the performance as much as possible constant over range, these areas have been covered twice, with mutually displaced beams and with different baselines. Additionally, deserts showing rugged terrain (such as, e.g., the Gobi desert shown in the previous section) have been reacquired from a different viewing geometry, too, with nominal beams, in order to mitigate geometrical distortion phenomena such as shadow and layover. A systematic performance assessment has been carried out by comparing acquisitions over sandy areas with nominal TanDEM-X beams to the ones commanded with optimized imaging geometry. In the following, they will be referred to as "shallow" and "steep" beams, respectively. In particular, the error affecting the interferometric phase $\varphi$ can be estimated from the coherence and the equivalent number of looks employed for multilooking [2], [39]. The phase error ratio $\Delta \sigma_{\varphi}$ can be then expressed as

$$
\Delta \sigma_{\varphi}=\frac{\sigma_{\varphi, \text { steep }}}{\sigma_{\varphi, \text { shallow }}}
$$

where $\sigma_{\varphi, \text { steep }}$ and $\sigma_{\varphi, \text { shallow }}$ represent the standard deviations of the phase errors derived from the mean coherence for scenes acquired over desert areas with steep and shallow beams, respectively. Fig. 14 shows the phase error ratio $\Delta \sigma_{\varphi}$ as a function of the coherence of the shallow beam 


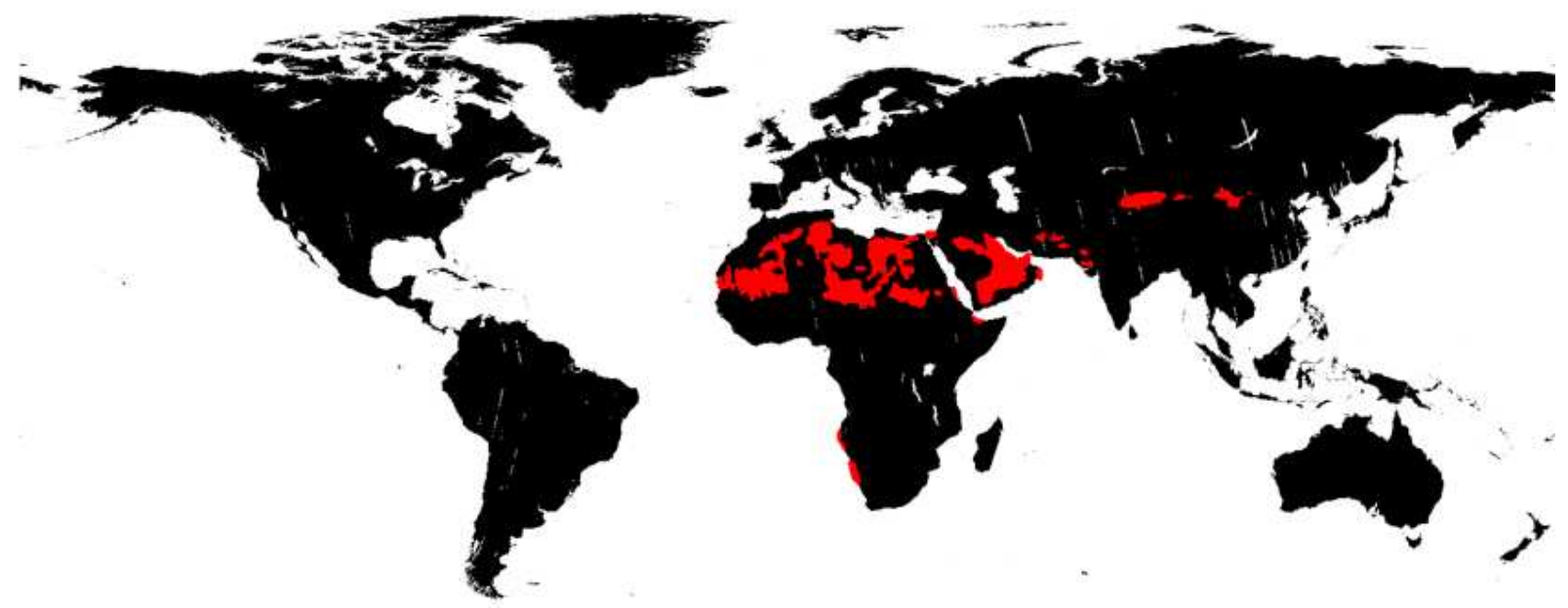

Fig. 12. Reacquisition of sandy deserts (highlighted in red) has been planned with steeper incidence angles in order to minimize the effect of SNR decorrelation and to improve the overall DEM quality.

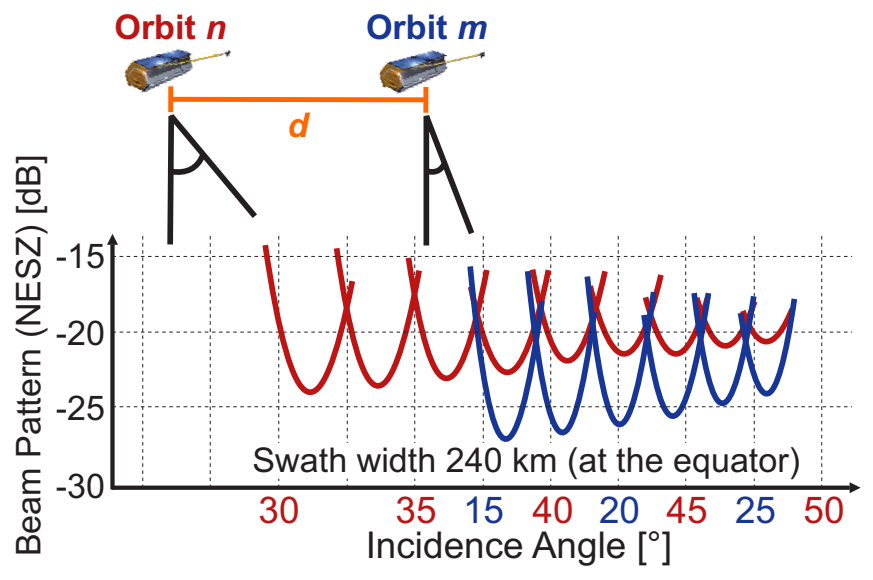

Fig. 13. The specific orbit employed by TanDEM-X allows, for a given flight direction, to acquire the same ground coordinates from different positions. For nominal mission operation, the incidence angles range typically between $29^{\circ}$ and $49^{\circ}$ (orbit $n$, depicted in red). Sandy deserts can be reacquired with steeper incidence angles (orbit $m$ in dark blue). At the equator, due to the large range separation between contiguous orbits (indicated with $d$ ), angles between about $29^{\circ}$ and $36^{\circ}$ cannot be imaged from steeper angles. At higher latitudes, an increasing ground swath overlap can be exploited.

acquisitions, for about 6000 scenes. Each value is calculated taking into account two bistatic scenes with approximately the same ground coordinates. The use of steeper incidence angles brings a systematic performance improvement: about $85 \%$ of the values lie in the region below the red line $\left(\Delta \sigma_{\varphi}<1\right)$, which corresponds to a reduction of the phase error. This is more evident for low coherence values and leads, in turn, to a significant increase of the phase unwrapping stability as well as of the relative vertical accuracy of the resulting DEM. On the other hand, the phase error ratio appears to be more variable at higher coherence, where nominal beam acquisitions already provide a sufficient data quality.

In order to provide an up-to-date monitoring of the performance of the global TanDEM-X DEM, global mosaics are generated starting from quicklook images with reduced resolution [40]. A parameter of particular importance is the relative height accuracy, which represents the uncertainty due to noise-like disturbances (i.e., coherence loss). For TanDEM$\mathrm{X}$, the relative point-to-point height accuracy needs to be smaller than $2 \mathrm{~m}(4 \mathrm{~m})$ for areas showing predominant slopes smaller (bigger) than $20 \%$. These requirements are defined at a confidence level of $90 \%$ over a $1^{\circ} \times 1^{\circ}$ geocell. Multiple acquisitions can be exploited to increase the final DEM accuracy [2], as well as to improve the phase unwrapping quality [34]. Two mosaics of the relative height accuracy for a sandy desert located in the West Sahara (over Mali and Mauritania) are depicted in Fig. 15. The mosaics have a spatial resolution of about $300 \times 300 \mathrm{~m}^{2}$, the area extends by $1300 \times 500 \mathrm{~km}^{2}$ and is characterized by gentle longitudinal dunes with heights of a few tens of meters. The image on the top shows the height accuracy resulting from the two global coverages with nominal beams. According to the method described in [41] and [42], the specification of $2 \mathrm{~m}$ is achieved at a confidence level of only 80\%. On the bottom of Fig. 15 the height error distribution generated by combining the nominal coverage together with the optimized reacquisitions with steeper incidence angles is shown. In this case, the specification is met at a confidence level of $97 \%$.

In Fig. 16 the relative height error distribution is depicted for a sandy desert located in the North Sahara (over Libya and Egypt), for an area extending by about $800 \times 550$ $\mathrm{km}^{2}$. The image on the top has been generated from the two nominal coverages of TanDEM-X (with incidence angles ranging between $29^{\circ}$ and $49^{\circ}$ ). The specification of $2 \mathrm{~m}$ is achieved at a confidence level of about $83 \%$. The mosaic at the bottom has been generated by combining the nominal coverage together with the optimized reacquisitions (with incidence angles ranging between $14^{\circ}$ and $30^{\circ}$ ). Due to the presence of high and rugged sand dunes, crossing-orbit acquisitions have been commanded over this area, too, in order to mitigate geometrical distortions in the final DEM. In this case the specification is met at a confidence level of $93 \%$.

A noticeable and consistent performance improvement has been verified for other desert areas, too. It can be therefore 


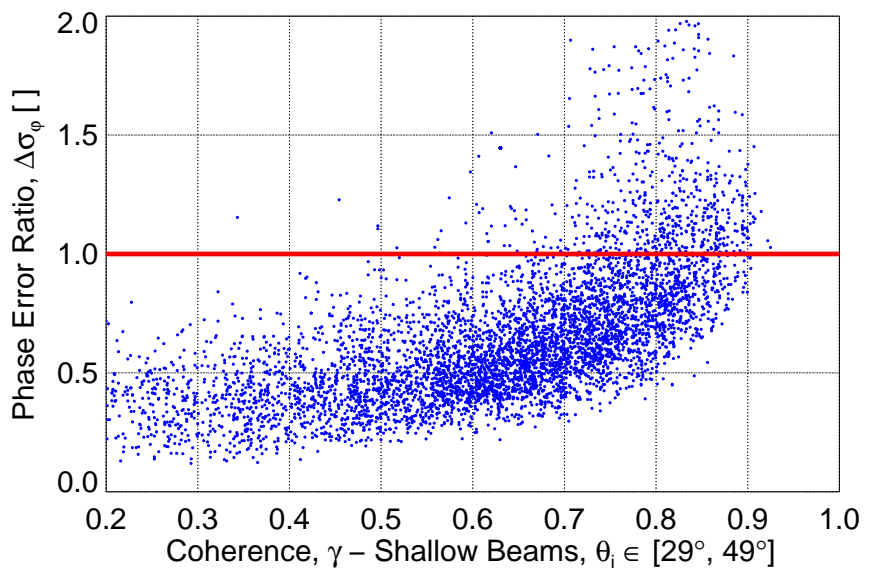

Fig. 14. Phase error ratio for TanDEM-X scenes acquired with steep and shallow incidence angles covering the same ground coordinates. The error ratio is calculated as in (4) and is plotted as a function of the coherence of the shallow beam acquisitions. In most cases the scene acquired with steeper incidence angle shows lower interferometric phase errors (corresponding to the values below the red line $\Delta \sigma_{\varphi}=1$ ).

concluded that the quality of the TanDEM-X InSAR products will be of very good quality over such critical regions, and it is expected that the occurrence of unreliable DEM values will be drastically reduced.

\section{CONCLUSIONS}

Sandy areas represent critical regions for the quality of spaceborne SAR sensor data. A performance analysis of TanDEM-X interferometric products over such areas has been presented, and the influence of several acquisition parameters has been investigated. The scattering mechanisms characterizing X-band radar images over sandy deserts have been detailed as well. In general, the weak power of the backscattered signal from sand strongly affects the SAR performance. However, if X-band spaceborne bistatic SAR surveys are acquired employing steeper incidence angles, a dramatic improvement in terms of SNR (up to $15 \mathrm{~dB}$ ) and coherence (typically above 0.8 ) can be achieved. The optimized combination of complementary viewing geometries allows moreover to further reduce geometrical distortions and to improve the unwrapping quality over deserts characterized by moderate to rugged sand topography (for this, the employment of shallow incidence angles is required). Possible approaches for the estimation of the backscatter coefficient have been discussed. Starting from the present investigations (overall, more than 6000 bistatic scenes have been evaluated), a dedicated reacquisition of such affected areas with steeper incidence angles has been executed. The promising results obtained so far demonstrate the outstanding interferometric capabilities of TanDEM-X, which will be able to provide the remote sensing community, even on such critical areas, with a unique DEM with unprecedented quality.

\section{ACKNOWLEDGMENT}

The authors would like to thank S. Kerkhoff (DLR-IMF) and Claudia Eger (DLR-DFD) for the processing of the experimental data. The TanDEM-X project is partly funded by the German Federal Ministry for Economic Affairs and Energy (Förderkennzeichen 50 EE 1035).

\section{REFERENCES}

[1] T. G. Farr, P. A. Rosen, E. Caro, R. Crippen, R. Duren, S. Hensley, M. Kobrick, M. Paller, E. Rodriguez, L. Roth, D. Seal, S. Shaffer, J. Shimada, J. Umland, M. Werner, M. Oskin, D. Burbank, and D. Alsdorf, "The Shuttle Radar Topography Mission," Rev. Geophys., vol. 45, 2007.

[2] G. Krieger, A. Moreira, H. Fiedler, I. Hajnsek, M. Werner, M. Younis, and M. Zink, "TanDEM-X: A satellite formation for high-resolution SAR interferometry," IEEE Trans. Geosci. Remote Sens., vol. 45, no. 11, pp. 3317-3341, November 2007.

[3] M. Martone, B. Bräutigam, P. Rizzoli, C. Gonzalez, M. Bachmann, and G. Krieger, "Coherence evaluation of TanDEM-X interferometric data," ISPRS J. of Photogr. Remote Sens., vol. 73, pp. 21-29, September 2012.

[4] B. Bräutigam, P. Rizzoli, M. Martone, M. Bachmann, D. Schulze, G. Krieger, and M. Zink, "TanDEM-X acquisition and quality overview with two global coverages," in Proc. Int. Geosci. Remote Sens. Symp., Melbourne, Australia, July 2013.

[5] M. Martone, P. Rizzoli, B. Bräutigam, and G. Krieger, "First two years of TanDEM-X mission: interferometric performance overview," Radio Science, vol. 48, pp. 617-627, October 2013.

[6] M. Martone, B. Bräutigam, and G. Krieger, "Decorrelation effects in bistatic TanDEM-X data," in Proc. Int. Geosci. Remote Sens. Symp., Munich, Germany, July 2012, pp. 5558-5561.

[7] D. B. Tridon, M. Bachmann, D. Schulze, C. Ortega-Míguez, M. D. Polimeni, M. Martone, J. Böer, and M. Zink, "TanDEM-X: DEM acquisition in the third year era," Int. J. of Space Science and Engineering, vol. 1, no. 4, pp. 367-381, 2013.

[8] L. R. Denham, "Seismic interpretation," Proc. IEEE, vol. 72, no. 10, pp. 1255-1265, October 1984.

[9] A. Elsherbini and K. Sarabandi, "Mapping of sand layer thickness using SAR interferometry," IEEE Trans. Geosci. Remote Sens., vol. 48, no. 9, pp. 3350-3359, September 2010.

[10] M. Martone, B. Bräutigam, P. Rizzoli, and G. Krieger, "TanDEM-X performance over sandy areas," in Proc. EUSAR, Berlin, Germany, June 2014.

[11] G. G. Schaber, J. F. McCauley, C. S. Breed, and G. R. Olhoeft, "Shuttle Imaging Radar: physical controls on signal penetration and subsurface scattering in the eastern Sahara," IEEE Trans. Geosci. Remote Sens., no. 4, pp. 603-623, July 1986.

[12] P. J. Curlander and R. N. McDonough, Synthetic Aperture Radar Systems and Signal Processing. New York, NY, USA: John Wiley and Sons, 1991.

[13] T. G. Farr, C. Elachi, P. Hartl, and K. Chowdhury, "Microwave penetration and attenuation in desert soil: a field experiment with the Shuttle Imaging Radar," IEEE Trans. Geosci. Remote Sens., no. 4, pp. 590-594, July 1986

[14] J. F. McCauley, G. G. Schaber, C. S. Breed, M. J. Grolier, C. V. Haynes, B. Issawi, C. Elachi, and R. Bloom, "Subsurface valleys and geoarchaeology of the Eastern Sahara revealed by shuttle radar," Science, vol. 218, pp. 1004-1020, December 1982.

[15] G. G. Schaber and C. S. Breed, "The importance of SAR wavelength in penetrating blow sand in Northern Arizona," Remote Sens. of Environ., vol. 69, no. 2, pp. 87-104, August 1999.

[16] J. Hoffmann and D. Walter, "How complementary are SRTM-X and -C band digital elevation models?" Photogr. Eng. and Remote Sens., vol. 72, no. 3, pp. 261-268, March 2006.

[17] R. Linck, T. Busche, S. Buckreuss, J. W. E. Fassbinder, and S. Seren, "Possibilities of archaeological prospection by high-resolution X-band satellite radar - A case study from Syria," Archaeol. Prospect., vol. 20, pp. 97-108, May 2013.

[18] D. Just and R. Bamler, "Phase statistics of interferograms with applications to synthetic aperture radar," Applied Optics, vol. 33, no. 20, pp. 4361-4368, July 1994.

[19] R. N. Treuhaft and P. R. Siqueira, "The vertical structure of vegetated land surfaces from interferometric and polarimetric radar," Radio Science, vol. 35, no. 1, pp. 131-177, 2000.

[20] M. Villano and G. Krieger, "Impact of azimuth ambiguities on interferometric performance," IEEE Geosci. Remote Sens. Lett., vol. 9, no. 5, pp. 896-900, September 2012.

[21] M. Martone, B. Bräutigam, and G. Krieger, "Quantization effects in TanDEM-X data," IEEE Trans. Geosci. Remote Sens., vol. 53, no. 2, pp. 583-597, February 2015. 


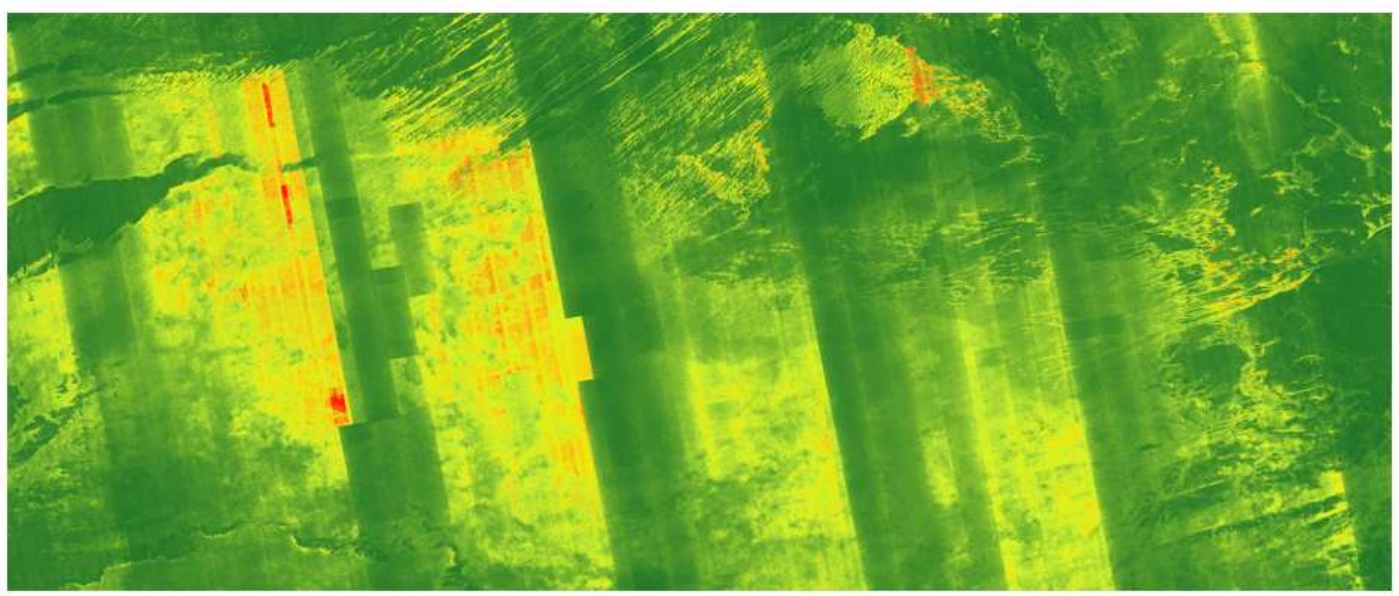

Relative Height Error ( $\sigma$, Single Point) $[\mathrm{m}]$
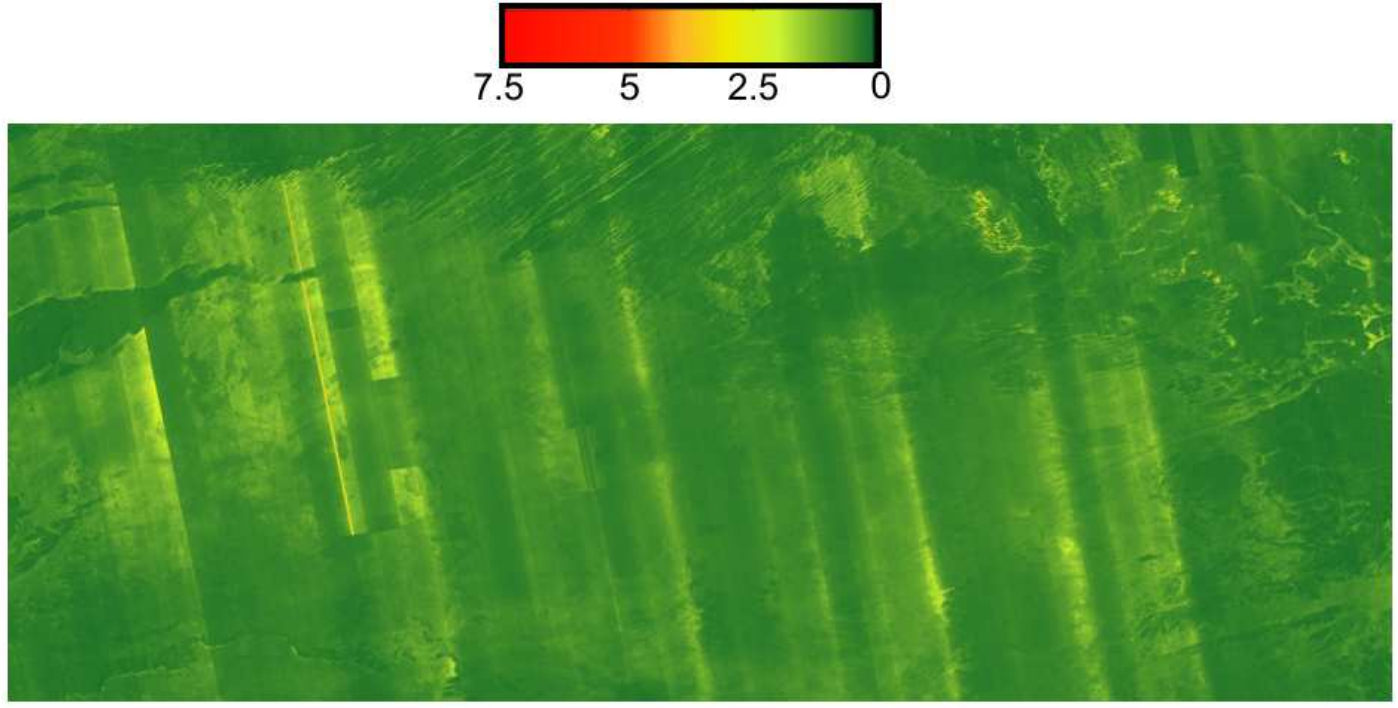

Fig. 15. Relative height error distribution of a sandy area located in the western Sahara (latitude $\in\left[18^{\circ}, 23^{\circ}\right]$, longitude $\in\left[-12^{\circ}, 0^{\circ}\right]$ ) generated from quicklook mosaics. The resolution is about $300 \times 300 \mathrm{~m}^{2}$. The image on the top has been generated from the two nominal coverages of TanDEM-X (with incidence angles ranging between $29^{\circ}$ and $49^{\circ}$ ). The mosaic at the bottom has been generated by combining the nominal coverages together with the optimized reacquisitions (with incidence angles ranging between $14^{\circ}$ and $30^{\circ}$ ).

[22] A. Y. Nashashibi, K. Sarabandi, F. A. Al-Zaid, and S. Alhumaidi, "Characterization of radar backscatter response of sand-covered surfaces at millimeter-wave frequencies," IEEE Trans. Geosci. Remote Sens., vol. 50, no. 6, pp. 2345-2354, June 2012.

[23] F. T. Ulaby, R. K. Moore, and A. Fung, Microwave Remote Sensing. Active and Passive, Vol. II. Reading, MA, USA: Addison-Wesley, 1982.

[24] C. Mätzler, "Microwave permittivity of dry sand," IEEE Trans. Geosci. Remote Sens., vol. 36, no. 1, pp. 317-319, January 1998.

[25] H. K. A. Jassar and K. S. Rao, "Observation of atmospheric effects on repeat-pass interferometric synthetic aperture radar over the Kuwait desert," Int. J. of Remote Sens., vol. 32, no. 22, pp. 7613-7629, July 2011.

[26] K. S. Rao and H. K. A. Jassar, "Error analysis in the digital elevation model of Kuwait desert derived from repeat pass synthetic aperture radar interferometry," J. App. Remote Sens., vol. 4, no. 1, September 2010.

[27] F. Gatelli, A. M. Guarnieri, F. Parizzi, P. Pasquali, C. Prati, and F. Rocca, "The wavenumber shift in SAR interferometry," IEEE Trans. Geosci. Remote Sens., vol. 32, no. 4, pp. 855-865, July 1994.

[28] Z. Dong, T. Wang, and X. Wang, "Geomorphology of the megadunes in the Badain Jaran Desert," Geomorphology, vol. 60, no. 1.

[29] K. Pye and H. Tsoar, Aeolian Sand and Sand Dunes. Berlin, Germany: Springer, 2009.

[30] H. Lee and J. G. Liu, "Spatial decorrelation due to the topography in the interferometric SAR coherence image," in Proc. Int. Geosci. Remote
Sens. Symp., p. 485.

[31] — "Analysis of topographic decorrelation in SAR interferometry using ratio coherence imagery," IEEE Trans. Geosci. Remote Sens., vol. 39, no. 2, pp. 223-232, February 2001.

[32] M. Eineder, M. Hubig, and B. Milcke, "Unwrapping large interferograms using the minimum cost flow algorithm," in Proc. Int. Geosci. Remote Sens. Symp., Seattle, WA, July 1998, pp. 83-87.

[33] T. Fritz, H. Breit, U. Balss, N. Yague-Martinez, C. Rossi, A. Niedermaier, M. Lachaise, and F. Rodriguez-Gonzalez, "Processing of interferometric TanDEM-X data," in Proc. EUSAR, Aachen, Germany, June 2010.

[34] M. Lachaise, U. Balss, T. Fritz, and H. Breit, "The dual-baseline interferometric processing chain for the TanDEM-X mission," in Proc. Int. Geosci. Remote Sens. Symp., Munich, Germany, July 2012, pp. $5562-5565$.

[35] F. J. Harris, "On the use of windows for harmonic analysis with the discrete Fourier transform," Proc. IEEE, vol. 66, no. 1, pp. 51-83, January 1978.

[36] J.-S. Lee, K. Papathanassiou, T. L. Ainsworth, M. R. Grunes, and A. Reigber, "A new technique for noise filtering of SAR interferometric phase images," IEEE Trans. Geosci. Remote Sens., vol. 36, no. 6, pp. 1456-1465, September 1998.

[37] G. Vasile, E. Trouv, J. Lee, and V. Buzuloiu, "Intensitity-driven adaptiveneighborhood technique for polarimetric and interferometric SAR pa- 


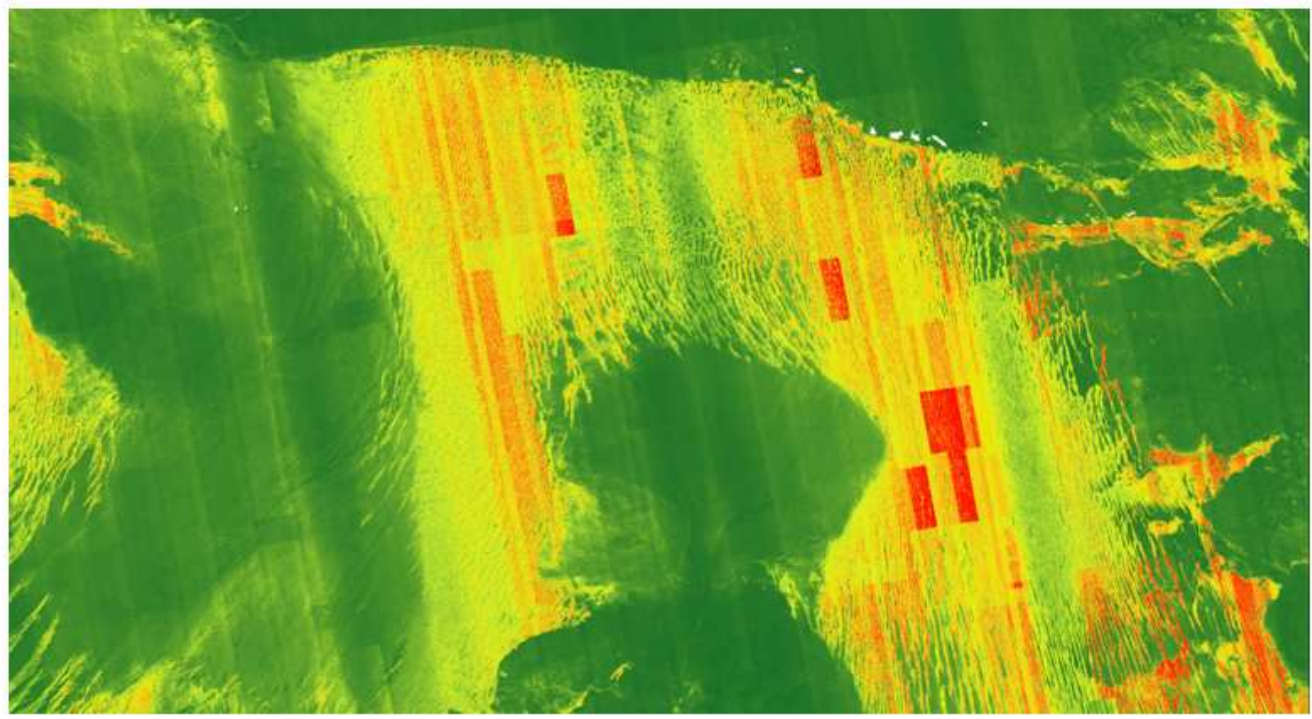

Relative Height Error ( $\sigma$, Single Point) $[\mathrm{m}]$
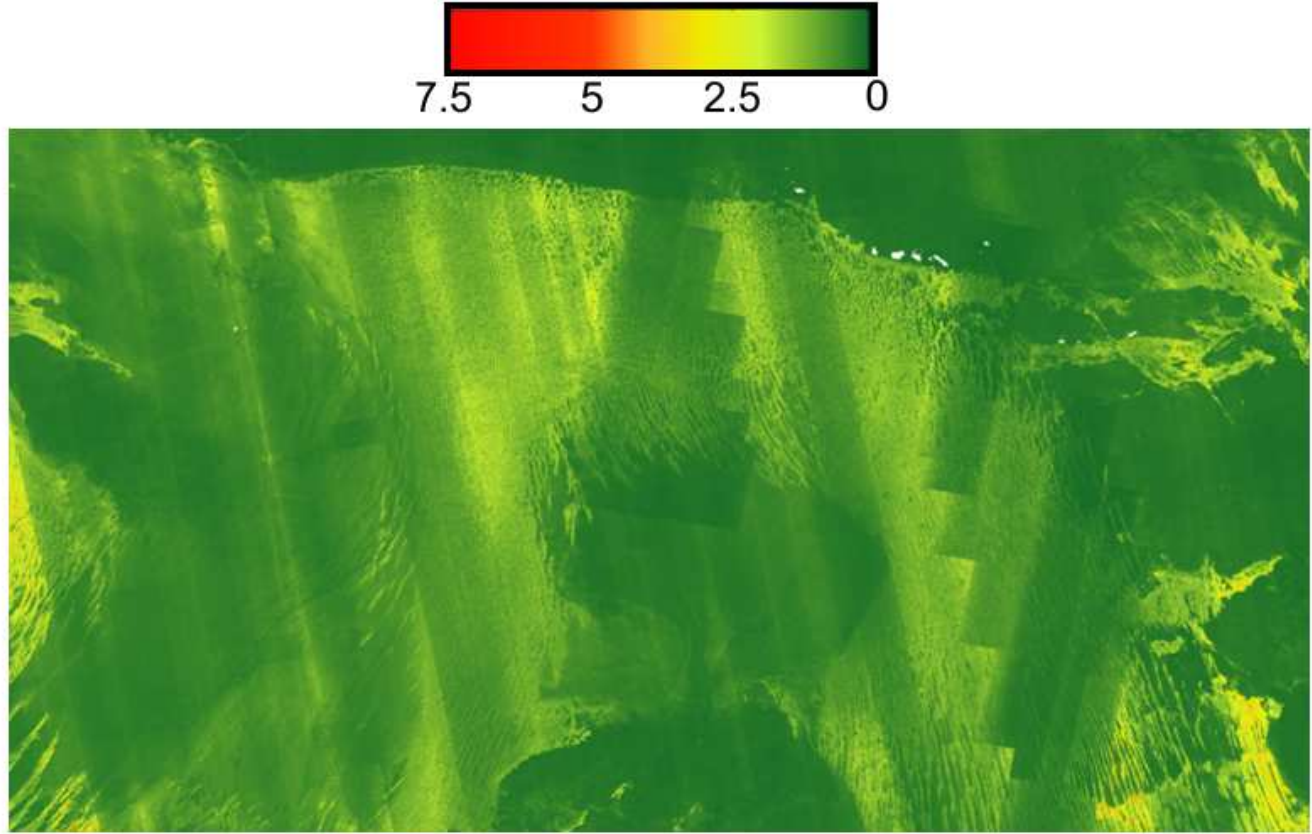

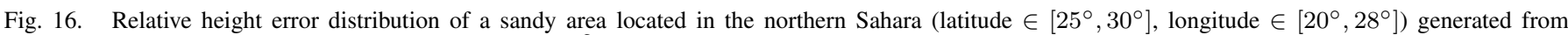
quicklook mosaics. The resolution is about $300 \times 300 \mathrm{~m}^{2}$. The image on the top has been generated from the two nominal coverages of TanDEM-X (with incidence angles ranging between $29^{\circ}$ and $49^{\circ}$ ). The mosaic at the bottom has been generated by combining the nominal coverages together with the optimized reacquisitions (with incidence angles ranging between $14^{\circ}$ and $30^{\circ}$ ). Due to the presence of high and rugged sand dunes, crossing-orbit acquisitions have been commanded over this area as well, in order to mitigate geometrical distortions in the final DEM.

rameters estimation," IEEE Trans. Geosci. Remote Sens., vol. 44, no. 6, pp. 1609-1621, June 2006.

[38] D. B. Tridon, M. Bachmann, D. Schulze, M. D. Polimeni, M. Martone, J. Böer, and M. Zink, "TanDEM-X DEM difficult terrain and Antarctica acquisitions towards the planning of the science phase," in Proc. EUSAR, Berlin, Germany, June 2014.

[39] J.-S. Lee, K. W. Hoppel, S. A. Mango, and A. R. Millerand, "Intensity and phase statistics of multilook polarimetric and interferometric SAR imagery," IEEE Trans. Geosci. Remote Sens., vol. 32, no. 5, pp. 10171028, September 1994.

[40] P. Rizzoli, M. Martone, and B. Bräutigam, "Global interferometric coherence maps from TanDEM-X quicklook data," IEEE Geosci. Remote Sens. Lett., vol. 11, no. 11, pp. 1861-1865, November 2011.

[41] P. Rizzoli, B. Bräutigam, T. Kraus, M. Martone, and G. Krieger,
"Relative height error analysis of TanDEM-X elevation data," ISPRS J. of Photogr. Remote Sens., vol. 73, pp. 30-38, September 2012.

[42] C. Gonzalez, B. Bräutigam, M. Martone, and P. Rizzoli, "Relative height error estimation method for TanDEM-X DEM products," in Proc. EUSAR, Berlin, Germany, June 2014. 